\title{
夏季纳木错湖水蒸发对当地大气水汽贡献的方法探讨: 基于水体稳定同位素的估算
}

\author{
徐彦伟 ${ }^{(1)}$, 康世昌 $\left.{ }^{(12}\right)^{*}$, 张玉兰 ${ }^{(1)}$, 张拥军 ${ }^{(1)}$ \\ (1) 中国科学院青藏高原研究所青藏高原环境变化与地表过程重点实验室, 北京 100085; \\ (2) 中国科学院冰冻圈科学国家重点实验室, 兰州 730000 \\ * 联系人, E-mail: shichang.kang@itpcas.ac.cn \\ 2010-11-10 收稿, 2011-02-24 接受 \\ 全球变化研究国家重大科学研究计划(2010CB951401)、中国科学院知识创新工程重要方向项目(KZCX2-YW-145)和国家自然科学基金重点 \\ 项目(40830743)资助
}

\begin{abstract}
摘要 青藏高原中部和南部在夏季风期间的降水主要来自印度季风输送的水汽和高原自身蒸 发的水汽. 然而, 目前两种水汽对降水的贡献率还不清楚. 夏季风期间(6 9月), 纳木错湖区大 气降水、河水中过量元明显比纳木错以南地区降水中过量氞高, 这反映了纳木错湖水蒸发水汽 与当地大气水汽的混合. 本文根据地表水体蒸发水汽对当地大气水汽贡献率的估算理论, 基于 相关水体(降水、河水、大气水汽和湖水) 中稳定同位素数据, 初步估算出近年夏季纳木错湖水 蒸发水汽对当地大气水汽的贡献率平均约为 $28.4 \%$ 31.1\%.
\end{abstract}

\section{关键词}

大气水汽

稳定同位素

过量氞

蒸发水汽

纳木错
青藏高原内陆水汽循环的研究, 对充分认识青 藏高原不同区域水汽来源和降水时空分布有重要的 作用. 春季和夏季期间，作为一个强大的热源，青藏 高原地表大量的潜热和感热的输出 ${ }^{[1 ~ 3]}$, 不仅在印度 季风形成中起到了重要的作用 ${ }^{[4 \sim 6]}$, 而且对全球大气 环流也有一定的影响 ${ }^{[7,8]}$. 同时, 随着地表热量的大 量输出和白天大气对流运动增强 ${ }^{[9,10]}$, 青藏高原上出 现明显的地表水汽再循环过程, 有大量地表蒸发水 汽进人大气. 其中, 相当一部分蒸发水汽来自青藏高 原为数众多的湖泊, 这些湖面总面积达到 44993.3 $\mathrm{km}^{2}[11]$. 因此, 地表蒸发水汽尤其是湖水蒸发水汽对 青藏高原当地大气水汽的贡献不容忽视. 已有研究 对青藏高原内陆水汽循环及其对大气水汽的贡献给 出了一些定性描述, 如杨伟愚等人 ${ }^{[12]}$ 研究发现青藏 高原西部的降水、蒸发和向土壤中渗透接近于平衡, 其水分循环主要是局地的内循环; 姚檀栋等人 ${ }^{[13]}$ 通 过研究唐古拉山地区降雪 $\delta^{18} \mathrm{O}$ 特征发现部分降雪的 水汽来源于高原内陆蒸发水汽; Kurita 和 Yamada ${ }^{[14]}$
通过对那曲地区 2004 年夏季降水、近地面大气水汽 和蒸腾水汽中稳定同位素的对比研究发现局地蒸发 水汽对绝大部分降水水汽有贡献. 但是, 对于高原内 陆水汽对大气水汽的贡献率方面的定量研究工作目 前还很缺乏.

水体稳定同位素, 尤其是大气水汽中稳定同位 素, 已经成为对全球不同地区内陆水汽再循环进行 定性和定量研究的有用工具. 在南美亚马逊河流域, Gat 和 Matsui ${ }^{[15]}$ 通过建立平衡蒸腾模型并利用水体过 量気数据, 计算出流域内蒸发水汽贡献了约 $20 \%$ $40 \%$ 的区域大气水汽. 在北美五大湖区, Gat 等人 ${ }^{[16]}$ 运用类似的方法初步估算了夏季五大湖区湖水蒸发 水汽对当地大气水汽的贡献率. 在热带地区, Worden 等人 ${ }^{[17]}$ 通过对流层大气水汽和地表降水中稳定同位 素的对比研究, 认为热带地区对流层水汽主要来源 为海洋和陆地蒸发水汽. 在日本东部, Yamanaka 和 Shimizu ${ }^{[18]}$ 通过对 Kasumigaura 湖区不同地点大气水 汽的收集，计算了湖区大气水汽中不同来源水汽的 
混合以及湖水蒸发水汽对水汽的贡献率. 此外, 类似

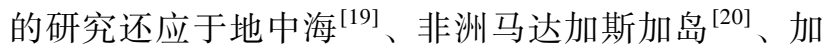
拿大 Slave 河三角洲 ${ }^{[21]}$ 、美国加利福尼亚和内华达 州 ${ }^{[22]}$ 等地区.

纳木错位于青藏高原中部(图 1), 念青唐古拉山 峰北麓, 西藏自治区当雄和班戈县境内, 介于 $30^{\circ} 30^{\prime} \sim$ $30^{\circ} 55^{\prime} \mathrm{N}, 90^{\circ} 16^{\prime} \sim 91^{\circ} 03^{\prime} \mathrm{E}$ 之间, 为我国第二大咸水 湖, 湖面海拔 $4718 \mathrm{~m}$, 面积约为 $2000 \mathrm{~km}^{2}{ }^{[23]}$. 纳木 错流域涵盖了高原地球系统的各个部分(如大气、冰 川、积雪、湖泊、土壤(冻土)、植被), 为研究青藏高 原地-气相互作用以及它们对区域气候和大气环流影 响提供了有利条件. 吕雅琼等人 ${ }^{[24]}$ 通过数值模拟发
现纳木错湖泊的存在会降低上空边界层顶高度，使 大气有限的水分和热量保存在较低的边界层中, 这 使得湖区蒸发水汽能够同外来输人水汽充分混合. 还有研究发现: 在湖面解冻期, 纳木错湖水蒸发一直 都较强, 其中季风后期(秋季和初冬季节)的蒸发是一 年中最强的 ${ }^{[25]}$. 这些都说明纳木错湖区蒸发水汽循 环, 尤其是湖水蒸发水汽可能会对湖区的大气系统 产生一定的影响.

基于以上考虑，本文将探讨一种水体稳定同位 素方法, 结合纳木错流域及毗邻地区水体 $\delta^{18} \mathrm{O}, \delta^{2} \mathrm{H}$ 和过量氝 $(d)$ 数据, 来初步评估夏季纳木错湖水蒸发 水汽对当地大气水汽的贡献.

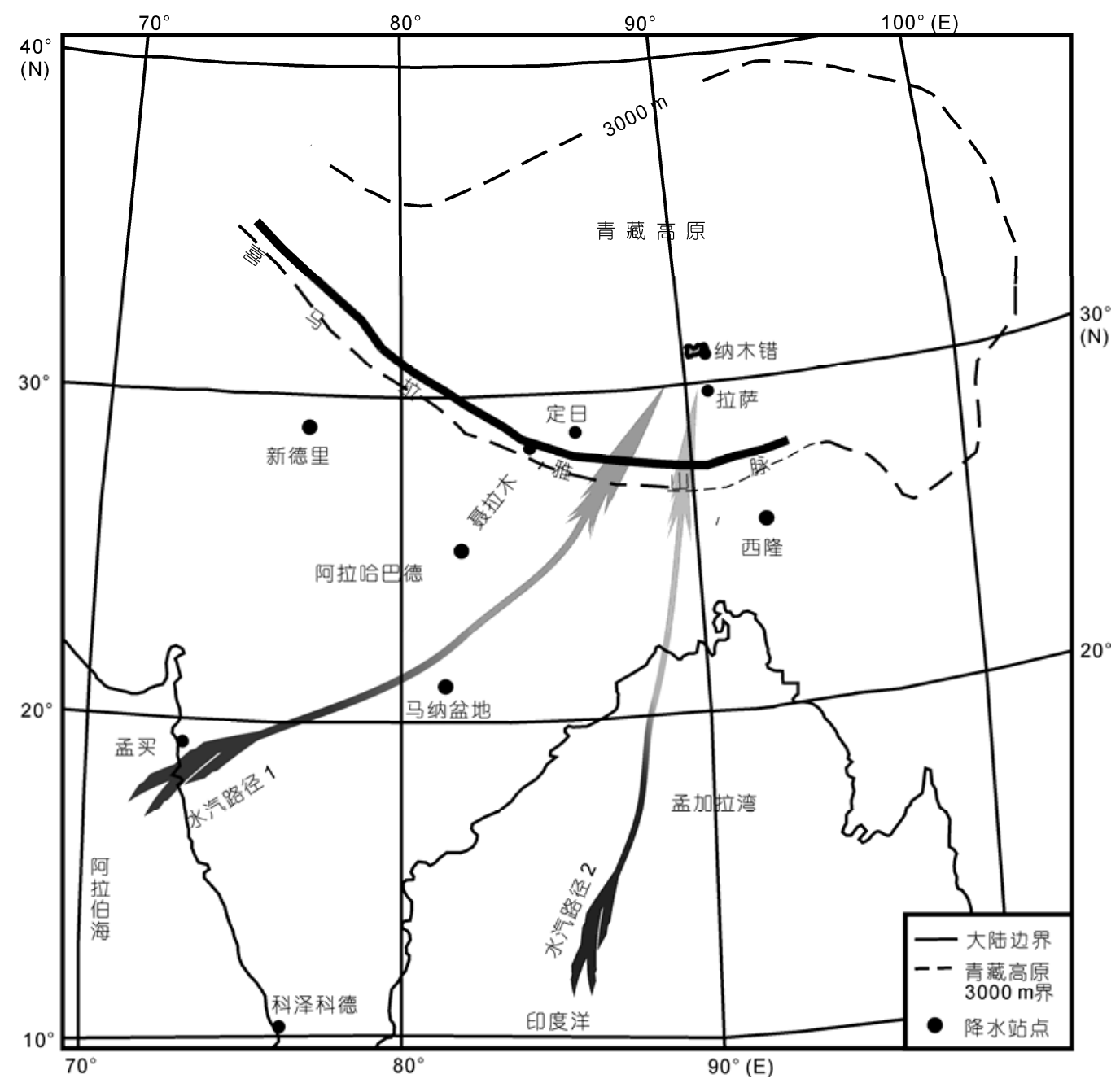

图 1 青藏高原南部和南亚次大陆大气降水采样站点分布及夏季纳木错流域两条典型印度季风水汽输送路径 水汽路径 1, 途经阿拉伯海路径; 水汽路径 2, 途经孟加拉湾路径. 这 2 条水汽输送路径主要根据 NOAA 的 HYSPLIT 气团轨迹模型 (http://ready.arl.noaa.gov/hysplit-bin/trajtype.pl?runtype=archive)结合 GDAS 历史气象数据库(2006 2009 年 6 9月)模拟的气团(地面以上 $500 \mathrm{~m})$ 后向轨迹图得出 


\section{1 理论基础}

大洋区域大气水汽中稳定同位素含量由海-气相 互作用过程控制 ${ }^{[26,27]}$ ，这些过程也决定了海洋性水 汽中 $d$ 值 $^{[16]}$ ( $d$ 值为过量氝值, 其定义为 $d=\delta^{2} \mathrm{H}$ $\left.-8 \delta^{18} \mathrm{O}^{[28]}\right)$. 海洋性水汽随着气团向大陆内部传输, 并在传输过程中由于不断的降水, 水汽中 ${ }^{18} \mathrm{O}$ 和 ${ }^{2} \mathrm{H}$ 逐渐贫化, 如果传输过程中没有大陆性水汽的加人, 水汽中 $d$ 值会始终保持不变 ${ }^{[29]}$. 然而, 部分降落到地 面的降水事实上会通过地表水体的蒸发作用和植被 的蒸腾作用返回大气，其中蒸腾作用产生的水汽不 会改变之前大气水汽中稳定同位素含量(由于未发生 同位素分馏 $)^{[16,30]}$, 而地表水体蒸发水汽则成为具有 较高 $d$ 值的大陆性水汽返回大气，与之前具有相对较 低 $d$ 值的大气水汽迅速混合, 这样导致混合后的大气 水汽 $d$ 值高于混合前的水汽 $d$ 值 ${ }^{[16]}$. 因此, 可以利用 混合前、后大气水汽 $d$ 值的变化来评估一个区域地表 水体蒸发水汽对大气水汽的贡献比率 ${ }^{[15,20,22]}$. 为了评 估某一个地表水体蒸发水汽对当地大气水汽的贡献, 需要了解该水体所在区域未受该水体蒸发水汽影响 的大气水汽(一般为该水体上风向区域输人的水汽)以 及该水体蒸发水汽中 $d$ 值.

假设某水体蒸发水汽对当地大气水汽贡献率为 $x$ $(0 \leqslant x<1)$, 那么由上风向区域输人该地的水汽贡献率 则为 $1-x$, 则当地大气水汽中过量氛 $d_{\mathrm{A}}$ 可由下式表 示:

$$
d_{\mathrm{A}}=d_{\mathrm{A}}^{\prime}(1-x)+d_{\mathrm{E}} x,
$$

其中, $d_{\mathrm{A}}, d_{\mathrm{A}}^{\prime}$ 和 $d_{\mathrm{E}}$ 分别为当地大气水汽、上风向区域 输人大气水汽和该水体蒸发水汽的 $d$ 值. 变换式(1), 可得蒸发水汽对当地大气水汽贡献率 $(x)$ 的计算公式:

$$
x=\frac{d_{\mathrm{A}}-d_{\mathrm{A}}^{\prime}}{d_{\mathrm{E}}-d_{\mathrm{A}}} .
$$

对于 $d_{\mathrm{E}}$, 可由该地表水体蒸发水汽稳定同位素 含量 $\delta_{\mathrm{E}}$ 得出. 基于一个简化的 Craig-Gordon 水体蒸 发模型 ${ }^{[26]}, \delta_{\mathrm{E}}$ 由如下公式估算 ${ }^{[31]}$ :

$$
\begin{aligned}
\delta_{\mathrm{E}} & =\frac{\left(\delta_{\mathrm{W}}-\varepsilon^{*}\right) / \alpha^{*}-h \delta_{\mathrm{A}}-\varepsilon_{\mathrm{K}}}{1-h+\varepsilon_{K}} \\
& \approx \frac{\left(\delta_{\mathrm{W}}-\varepsilon^{*}\right) / \alpha^{*}-h \delta_{\mathrm{A}}-\varepsilon_{\mathrm{K}}}{1-h},
\end{aligned}
$$

其中, $\delta_{\mathrm{A}}$ 和 $\delta_{\mathrm{W}}$ 分别为当地大气水汽和该地表水体中 稳定同位素含量, $h$ 为水面大气相对湿度, 液态水和 蒸发水汽间同位素平衡分馏系数 $\alpha^{*}$ 可由基于水汽界
面温度的经验公式进行计算 ${ }^{[32]}, \varepsilon^{*}$ 为平衡富集系数 $\left(\varepsilon^{*}=\alpha^{*}-1\right)$, 动力富集系数 $\varepsilon_{\mathrm{K}}$ 由基于大气边界层条件 和湿度条件的经验公式 $\varepsilon_{\mathrm{K}}=C_{\mathrm{K}}(1-h)$ 计算 ${ }^{[33]}$, 在一般 的湖泊蒸发条件下, ${ }^{18} \mathrm{O}$ 和 ${ }^{2} \mathrm{H}$ 所对应的常数 $C_{\mathrm{K}}$ 通常 分别取值为 0.0142 和 $0.0125^{[33]}$.

接着, 把式(3)分别用 ${ }^{18} \mathrm{O}$ 和 ${ }^{2} \mathrm{H}$ 表示, 得到下列 方程组:

$\delta_{E}\left({ }^{18} \mathrm{O}\right)$

$$
=\frac{\left(\delta_{\mathrm{W}}\left({ }^{18} \mathrm{O}\right)-\varepsilon^{*}\left({ }^{18} \mathrm{O}\right)\right) / \alpha^{*}\left({ }^{18} \mathrm{O}\right)-h \delta_{\mathrm{A}}\left({ }^{18} \mathrm{O}\right)-\varepsilon_{\mathrm{K}}\left({ }^{18} \mathrm{O}\right)}{1-h},
$$

$\delta_{E}\left({ }^{2} \mathrm{H}\right)$

$$
=\frac{\left(\delta_{\mathrm{W}}\left({ }^{2} \mathrm{H}\right)-\varepsilon^{*}\left({ }^{2} \mathrm{H}\right)\right) / \alpha^{*}\left({ }^{2} \mathrm{H}\right)-h \delta_{\mathrm{A}}\left({ }^{2} \mathrm{H}\right)-\varepsilon_{\mathrm{K}}\left({ }^{2} \mathrm{H}\right)}{1-h} .
$$

根据过量氞定义 ${ }^{[28]}$ 和 $\varepsilon_{\mathrm{K}}$ 的经验计算公式 ${ }^{[33]}$, 把 $\delta_{\mathrm{E}}\left({ }^{2} \mathrm{H}\right)=d_{\mathrm{E}}+8 \delta_{\mathrm{E}}\left({ }^{18} \mathrm{O}\right), \delta_{\mathrm{A}}\left({ }^{2} \mathrm{H}\right)=d_{\mathrm{A}}+8 \delta_{\mathrm{A}}\left({ }^{18} \mathrm{O}\right), \varepsilon_{\mathrm{K}}\left({ }^{2} \mathrm{H}\right)=$ $0.0125(1-h)$ 和 $\varepsilon_{\mathrm{K}}\left({ }^{18} \mathrm{O}\right)=0.0142(1-h)$ 代人式 $(5)$, 联立式 (4)得到:

$$
d_{\mathrm{E}}=\frac{A-h d_{\mathrm{A}}-B}{1-h}+0.1011,
$$

其中 $A=\frac{\delta_{\mathrm{W}}\left({ }^{2} \mathrm{H}\right)}{\alpha^{*}\left({ }^{2} \mathrm{H}\right)}-\frac{8 \delta_{\mathrm{W}}\left({ }^{18} \mathrm{O}\right)}{\alpha^{*}\left({ }^{18} \mathrm{O}\right)}, B=\frac{\varepsilon^{*}\left({ }^{2} \mathrm{H}\right)}{\alpha^{*}\left({ }^{2} \mathrm{H}\right)}-\frac{8 \varepsilon^{*}\left({ }^{18} \mathrm{O}\right)}{\alpha^{*}\left({ }^{18} \mathrm{O}\right)}$.

公式(6)可以改写为

$$
d_{\mathrm{E}}-d_{\mathrm{A}}=\frac{A-d_{\mathrm{A}}-B}{1-h}+0.1011 \text {. }
$$

把上式代人式(2), 得到:

$$
\mathrm{x}=\frac{\left(d_{\mathrm{A}}-d_{\mathrm{A}}^{\prime}\right)(1-h)}{A-d_{\mathrm{A}}-B+0.1011(1-h)} .
$$

值得注意的是, 上述所有公式中相关参数的值 都是用十进制表示的，如 $d_{\mathrm{A}}=0.010, h=0.6$.

综上, 如果确定了 $h, \alpha^{*}, \delta_{\mathrm{W}}, d_{\mathrm{A}}$ 和 $\left(d_{\mathrm{A}}-d_{\mathrm{A}}{ }^{\prime}\right)$ 的值, 就可以由公式(8)估算出该水体蒸发水汽对当地大气 水汽的贡献率 $(x)$.

本文中, 为了除去固体降水(雪和冰雱)在超低温 条件下形成冰晶时导致过量氝升高的影响 ${ }^{[34]}$, 我们 只估算纳木错湖区大气降水为降雨的夏季期间 (6 9 月)纳木错湖水蒸发水汽对当地大气水汽的贡献率.

\section{2 结果和讨论}

\section{1 夏季纳木错流域及其南部地区大气降水中稳 定同位素}

研究表明，夏季期间纳木错流域所处的青藏高 原中部地区降水主要来源于印度季风经由阿拉伯海 
和孟加拉湾这两条输送路径(图 1)带来的印度洋水 汽 $^{[35,36]}$. 前人的研究已经报道了一些位于这 2 条输送 路径上站点(图 1)夏季大气降水中的平均 $\delta^{18} \mathrm{O}, \delta^{2} \mathrm{H}$ 和 $d$ 数据(表 1). 从南至北, 以喜马拉雅山脉为分界线, 山脉南面的印度次大陆上的站点科泽科德、马纳盆 地、孟买、阿拉哈巴德、新德里、西隆夏季的平均 $\delta^{18} \mathrm{O}$, $\delta^{2} \mathrm{H}$ 和 $d$ 值分别介于-9.0\%o - $1.0 \%$, -64.0\%o - $2.0 \%$ o 和 $8.7 \%$ 1 1 .0\% 之间, 而位于喜马拉雅山脉及北部青 藏高原南部地区的聂拉木、定日和拉萨夏季平均 $\delta^{18} \mathrm{O}$,

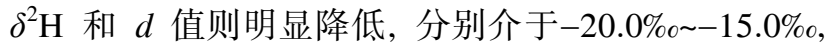
$-153.0 \%$ - $120.0 \%$ 和 $4.0 \%$ 5.0\% 之间. 对于两个区 域大气降水中 $\delta^{18} \mathrm{O}, \delta^{2} \mathrm{H}$ 值的明显差异, 是由于长距 离传输的印度洋水汽在翻越喜马拉雅山脉时形成大 量降水, 剩余水汽中 ${ }^{18} \mathrm{O},{ }^{2} \mathrm{H}$ 贫化严重导致的 ${ }^{[35,37]}$. 而对于喜马拉雅山脉及青藏高原南部站点降水平均 $d$ 值 $4.5 \%$ o比南面地区的 $9.0 \%$ 明显降低，目前还未有 相关研究给出一个解释. 理论上说, 由于相同的印度 洋水汽来源, 这些站点降水中 $d$ 值应与南部站点的相 差不大.

此外, 由图 1 和表 1 , 青藏高原南部的聂拉木、 定日和拉萨站 1998 2001 夏季降水 $d$ 均值非常接近, 说明这 3 个站点形成降水的水汽中 $d$ 值比较接近. 由 于纳木错与其西南上风向这 3 个站点有相同的印度 洋水汽来源 ${ }^{[36]}$ 和较近的距离 (与拉萨站的距离仅为 $120 \mathrm{~km}$, 图 1), 可知纳木错流域的输人水汽与这些站 点(特别是拉萨站)的大气水汽中 $d$ 值应该非常接近. 因此, 如果没有较高 $d$ 值的纳木错地表水体蒸发水汽
与这些输人水汽混合, 纳木错本地大气水汽中 $d$ 值相 对于输人水汽中 $d$ 值将会保持不变, 纳木错站降水中 $d$ 值也应该与这 3 个站点的值接近. 然而, 事实是纳 木错站 2005 2008 年夏季降水 $d$ 均值 $11.1 \%$ 。比这 3 个站点的 $d$ 均值 $4.5 \%$ 高 $6.6 \%$. 这就说明肯定有一定 量较高 $d$ 值的表面水体蒸发水汽加人了纳木错本地 大气水汽中. 研究表明, 每年纳木错湖水蒸发水汽量 占整个流域表面水体蒸发水汽总量的绝大部分 ${ }^{[38]}$. 因此, 这种纳木错流域降水中过量氝较高的现象很 可能是由于纳木错湖水蒸发水汽与上风向输送来的 水汽混合的结果.

\section{2 夏季纳木错流域河水中过量氝 $(d)$}

纳木错流域夏季降水中 $d$ 值较高的特征，在该 地区夏季河水中 $d$ 值上有很好的体现. 由表 2 , 纳木 错流域河水中 $d$ 均值为 $12.4 \%$, 明显高于纳木错南 部上风向区域河水中 $d$ 均值 $6.9 \%$ 。 其中, 位于纳木 错南岸的 $2,3,4,5$ 和 6 号采样河流河水中 $d$ 值都高 于 $13.0 \%$ ，表现得尤为明显. 这是由于这些河流的 主要水源为念青唐古拉山脉上降雪形成的冰川和 积雪的融水 ${ }^{[41]}$, 该地区夏季冰川融水 $d$ 均值约为 $14.0 \% 0^{[38]}$. 然而, 纳木错东岸和西岸的 1,7 和 8 号采 样河流河水中 $d$ 均值 $8.7 \%$ 仅比 $6.9 \%$ 稍高. 这是由于 这些河流的主要补给来源为降水和流域内广泛分布 的沼泽, 大量具有极低 $d$ 值的沼泽水 $(d$ 均值为 $-1.4 \% o^{[38]}$ )对河流的补给削弱了降水中较高 $d$ 值的 信号.

表 1 夏季季风季节(6 9 月)各站点大气降水中稳定同位素数据

\begin{tabular}{|c|c|c|c|c|c|}
\hline 站点名 & 数据时段 & $\delta^{18} \mathrm{O}$ 均值 $(\% \circ)$ & $\delta^{2} \mathrm{H}$ 均值 $(\% o)$ & $d$ 均值 $(\% o)$ & 数据来源 \\
\hline \multicolumn{6}{|c|}{ 喜马拉雅山脉南部地区 } \\
\hline 孟买 & $1961 \sim 1977$ & $-1.4 \pm 1.1$ & $-2.4 \pm 8.7$ & $8.7 \pm 4.0$ & \multirow{6}{*}{ [39] } \\
\hline 科泽科德 & $1998 \sim 1999$ & $-2.9 \pm 1.9$ & $-12.6 \pm 13.5$ & $10.2 \pm 2.1$ & \\
\hline 新德里 & $1961 \sim 1996$ & $-5.7 \pm 4.5$ & $-36.1 \pm 33.1$ & $7.8 \pm 6.7$ & \\
\hline 西隆 & $1969 \sim 1978$ & $-7.1 \pm 4.0$ & $-45.6 \pm 30.0$ & $10.8 \pm 5.2$ & \\
\hline 阿拉哈巴德 & 1980 & $-9.0 \pm 2.7$ & $-63.4 \pm 20.2$ & $8.6 \pm 2.3$ & \\
\hline 马纳盆地 & 1977 & $-4.7 \pm 2.5$ & $-29.4 \pm 19.0$ & $8.1 \pm 2.8$ & \\
\hline \multicolumn{6}{|c|}{ 青藏高原中南部地区 } \\
\hline 定日 & 2000 & $-19.5 \pm 4.2$ & $-152.0 \pm 32.3$ & $4.1 \pm 4.0$ & {$[40]$} \\
\hline 聂拉木 & $1998 \sim 2001$ & -15.7 & -120.4 & 5.0 & \multirow{2}{*}{ [35] } \\
\hline 拉萨 & $1998 \sim 2001$ & -18.4 & -142.7 & 4.2 & \\
\hline 纳木错 & $2005 \sim 2008$ & -19.6 & -146.6 & 11.1 & 本文 \\
\hline
\end{tabular}


表 2 夏季纳木错流域及其上风向区域河水中 $d$ 均值

\begin{tabular}{|c|c|c|c|c|c|}
\hline 编号 & 河流名 & $\delta^{18} \mathrm{O}(\%)$ & $\delta^{2} \mathrm{H}(\% o)$ & $d(\% \circ)$ & 数据来源 \\
\hline \multicolumn{6}{|l|}{ 纳木错流域 } \\
\hline 1 & 你亚曲 & -17.2 & -128.5 & 9.0 & \multirow{9}{*}{ 本文 } \\
\hline 2 & 朗玛 & -17.3 & -124.4 & 14.1 & \\
\hline 3 & 着砂曲 & -17.2 & -122.8 & 15.0 & \\
\hline 4 & 曲嘎切 & -16.1 & -115.8 & 13.2 & \\
\hline 5 & 拉弄 & -15.2 & -106.5 & 14.7 & \\
\hline 6 & 比郎 & -15.5 & -107.7 & 16.2 & \\
\hline 7 & 昂曲 & -17.1 & -128.4 & 8.1 & \\
\hline 8 & 波曲 & -16.0 & -118.7 & 9.2 & \\
\hline 平均值 & & -16.4 & -119.1 & 12.4 & \\
\hline \multicolumn{6}{|c|}{ 纳木错上风向区域(喜马拉雅山脉北部) } \\
\hline & 拉萨河 & - & - & $\sim 8.5$ & \multirow{7}{*}{ [42] } \\
\hline & 当雄河 & - & - & $\sim 7.5$ & \\
\hline & 雅鲁藏布江 & - & - & $\sim 7.5$ & \\
\hline & 日喀则河 & - & - & $\sim 6.5$ & \\
\hline & 定日河 & - & - & $\sim 6.0$ & \\
\hline & 拉龙山口冰川河 & - & - & $\sim 5.5$ & \\
\hline 平均值 & & & - & $\sim 6.9$ & \\
\hline
\end{tabular}

表 $32005 \sim 2008$ 年夏季 6 9 月纳木错湖水中 $\delta_{\mathrm{W}}{ }^{18} \mathrm{O}, \delta_{\mathrm{W}}{ }^{2} \mathrm{H}$ 值

\begin{tabular}{|c|c|c|c|c|c|c|c|c|c|c|}
\hline \multirow{2}{*}{ 年份 } & \multicolumn{2}{|c|}{ 6月 } & \multicolumn{2}{|c|}{ 7月 } & \multicolumn{2}{|c|}{8 月 } & \multicolumn{2}{|c|}{ 9月 } & \multicolumn{2}{|c|}{$6 \sim 9$ 月 } \\
\hline & $\delta_{\mathrm{W}}{ }^{18} \mathrm{O}(\% \circ)$ & $\delta_{\mathrm{w}}{ }^{2} \mathrm{H}(\% o)$ & $\delta_{\mathrm{W}}{ }^{18} \mathrm{O}(\% 0)$ & $\delta_{\mathrm{w}}{ }^{2} \mathrm{H}(\% o)$ & $\delta_{\mathrm{W}}{ }^{18} \mathrm{O}(\% 0)$ & $\delta_{\mathrm{w}}^{2} \mathrm{H}(\% o)$ & $\delta_{\mathrm{w}}{ }^{18} \mathrm{O}(\% 0)$ & $\delta_{\mathrm{w}}{ }^{2} \mathrm{H}(\% o)$ & $\delta_{\mathrm{W}}{ }^{18} \mathrm{O}(\% 0)$ & $\delta_{\mathrm{w}}^{2} \mathrm{H}(\% o)$ \\
\hline 2005 & - & - & - & - & -6.5 & -64.0 & -7.1 & -69.7 & -6.8 & -66.8 \\
\hline 2006 & -6.7 & -67.6 & -6.8 & -64.9 & -6.5 & -63.6 & - & - & -6.6 & -65.4 \\
\hline 2007 & -6.4 & -67.0 & -6.4 & -67.4 & -6.6 & -68.5 & -7.0 & -71.0 & -6.6 & -68.5 \\
\hline 2008 & -6.5 & -67.5 & -6.7 & -69.0 & -7.0 & -70.7 & -7.1 & -72.3 & -6.8 & -69.9 \\
\hline \multicolumn{9}{|c|}{ 2005 2008 年夏季平均值 } & -6.7 & -67.7 \\
\hline
\end{tabular}

a) -表示数据缺失

\section{3 夏季纳木错湖水中稳定同位素}

由表 3,2005 2008 年夏季纳木错湖水中 $\delta^{18} \mathrm{O}$, $\delta^{2} \mathrm{H}$ 值 (均值为 $-6.7 \%,-67.7 \%$ ) 远高于夏季河水中 $\delta^{18} \mathrm{O}, \delta^{2} \mathrm{H}$ 值(均值为 $-16.4 \%,-119.1 \%$ ), 这是由于湖 水长期经历强烈蒸发, 从而导致湖水中 ${ }^{18} \mathrm{O}$ 和 ${ }^{2} \mathrm{H}$ 逐 渐富集 ${ }^{[43]}$. 此外, 表 3 还表明: 夏季纳木错湖水中 $\delta^{18} \mathrm{O}, \delta^{2} \mathrm{H}$ 月际和年际变化幅度均较小. 因此, 纳木 错湖水中 $\delta^{18} \mathrm{O}, \delta^{2} \mathrm{H}$ 值较稳定, 2005 2008 年夏季纳木 错湖水中稳定同位素值可以代表近年夏季湖水中的 均值.

\section{4 夏季纳木错大气水汽中稳定同位素}

由于区域大气的不稳定性 ${ }^{[30,31]}$ 和强烈的季节 性 ${ }^{[44]}$, 直接测量大气水汽中稳定同位素含量 $\delta_{\mathrm{A}}$ 值比 较困难, 我们采用水汽-降水平衡法来估算夏季纳木
错流域大气水汽中稳定同位素含量 $\left(\delta_{\mathrm{A}}\right)$, 该方法已经 成功应用于全球许多地区的研究 ${ }^{[16,21,45,46]}$, 其计算公 式为 ${ }^{[46]}$

$$
\delta_{\mathrm{A}}=\left(\delta_{\mathrm{P}}-\varepsilon^{*}\right) / \alpha^{*},
$$

其中, $\delta_{\mathrm{P}}$ 为夏季降水稳定同位素平均值. 根据 2005 2008 年纳木错夏季平均气温 (约为 $7.8^{\circ} \mathrm{C}$ ) 和降水 $\delta^{18} \mathrm{O}$ 及 $\delta^{2} \mathrm{H}$ 均值(-19.6\% 和-146.6\% , 见表 1), 由公式(9) 计算得到 2005 2008 年纳木错流域大气水汽 $\delta^{18} \mathrm{O}$ 和 $\delta^{2} \mathrm{H}$ 均值 $\left(\delta_{\mathrm{P}}\right)$ 为 $-30.2 \%$ 。和 $-224.1 \%$, 相应的大气水汽 过量気均值 $\left(d_{\mathrm{A}}\right)$ 为 $17.6 \%$. 值得注意的是, 此公式中 相关参数的值是用十进制表示.

\section{5 夏季纳木错蒸发水汽对当地大气水汽贡献率}

(i ) 平均贡献率估算. 夏季期间, 纳木错降水 中 $d$ 均值的年际变化较小: $2005,2006,2007$ 和 2008 
年的 $d$ 均值分别为 $10.2 \%, 12.5 \%, 10.7 \%$ 和 $11.3 \%$. 因此, 纳木错站 2005 2008 年夏季降水 $d$ 均值 $11.1 \%$ 。 可代表近 10 年纳木错夏季大气降水中 $d$ 均值, 其与 上风向区域聂拉木、定日和拉萨站 1998 2001 年夏季 大气降水 $d$ 均值 $4.5 \%$ 之间的差值可代表两个区域夏 季大气水汽中 $d$ 的差值, 即 $\left(d_{\mathrm{A}}-d^{\prime}{ }_{\mathrm{A}}\right)$ 为 $6.6 \%$. 由上文, 2005 2008 年夏季纳木错湖水 $\delta_{\mathrm{W}}{ }^{18} \mathrm{O}$ 和 $\delta_{\mathrm{W}}{ }^{2} \mathrm{H}$ 均值分 别为 $-6.7 \%$ 和 $-67.7 \%$, 纳木错大气水汽 $d_{\mathrm{A}}$ 值为 $17.6 \%$. 同时, 由 2005 2008 年纳木错夏季平均气温 $7.8^{\circ} \mathrm{C}$, 可计算得到公式 $(8)$ 中的 $A$ 值为 $-0.00853, B$ 值 为 0.004231 . 把上述数据以及 $2005 ~ 2008$ 年纳木错站 夏季蒸发量加权平均相对湿度 (由于测湖面相对湿度 困难, 本文用湖区大气相对湿度代替, $h$ 介于 61\% 62\%)代人公式(8), 估算出近年夏季纳木错湖水 蒸发水汽对当地大气水汽平均贡献率约为 28.4\% 31.1\% . 由该估算结果，每年夏季期间，确实 有大量的纳木错湖水蒸发水汽进人当地大气, 并与 上风向区域传输过来的大气水汽混合, 使得纳木错 流域大气水汽和大气降水中过量気相对上风向区域 增大. 此外, 该估算结果与前人进行的有关地表大水 体蒸发水汽再循环研究的结果相似(表 4).

(ii) 误差分析. 由式(8), 估算的纳木错湖水蒸 发水汽对当地大气水汽的贡献率的准确度严重依赖 于 $h, d_{\mathrm{A}}$ 和 $\left(d_{\mathrm{A}}-d^{\prime}{ }_{\mathrm{A}}\right)$ 的准确度. 对于 $\left(d_{\mathrm{A}}-d^{\prime}{ }_{\mathrm{A}}\right)$ 的取值, 由

表 4 基于水体稳定同位素的地表大水体蒸发对大气水汽 贡献率研究结果对比

\begin{tabular}{clc}
\hline 蒸发水汽贡献率 $(\%)$ & \multicolumn{1}{c}{ 研究区域 } & 数据来源 \\
\hline $20 \sim 40$ & 南美亚马逊河流域 & {$[15]$} \\
$\sim 20$ & 美国加利福尼亚州中部 & {$[22]$} \\
& 和北部地区 & \\
$5 \sim 16$ & 北美五大湖区 & {$[16]$} \\
$\geqslant 16 ~ 50$ & 马达加斯加岛 Ihorty 湖区 & {$[20]$} \\
$10 \sim 20$ & 日本 Kasumigaura 湖区 & {$[18]$} \\
$0 \sim 45$ & 加拿大 Great Slave 湖区 & {$[21]$} \\
$28.4 ~ 31.1$ & 青藏高原纳木错湖区 & 本文 \\
\hline
\end{tabular}

表 5 公式 $(8)$ 中重要参数值改变 $\pm 5 \%$ 条件下纳木错湖水 蒸发水汽贡献率相应变化

\begin{tabular}{cccc}
\hline 参数(改变 $5 \% /-5 \%)$ & $d_{A}-d_{A}^{\prime}$ & $h$ & $d_{\mathrm{A}}$ \\
\hline 对应的贡献率变化 $(\%)$ & $5 /-5$ & $39.7 /-19.5$ & $-8.8 / 10.7$ \\
\hline
\end{tabular}

于它们是基于多年实地测量的数据得到, 因此较准 确, 误差较小. 然而, $d_{\mathrm{A}}$ 值是利用大气水汽和降水同 位素平衡方法估算得到, 水面相对湿度 $(h)$ 是由纳木 错站大气相对湿度代替, 这些数据将存在一定的误 差. 由表 5, $\left(d_{\mathrm{A}}-d^{\prime}{ }_{\mathrm{A}}\right)$ 值 5\%/-5\%的改变对贡献率估算 结果的影响最小 $(5 \% /-5 \%)$; 相对湿度 $(h)$ 变化 $5 \% /$ $-5 \%$ 对估算结果的影响最大，达到 $39.7 \% /-19.5 \% ; d_{\mathrm{A}}$ 值变化 5\%/-5\%对贡献率估算结果的影响也较大, 达 到-8.8\%/-10.7\%. 可见 $h$ 和 $d_{\mathrm{A}}$ 可能是估算结果产生 误差的主要因素.

\section{3 总结与展望}

夏季印度季风季节, 由于印度洋水汽的长距离 传输, 印度次大陆地区大气降水中 $\delta^{18} \mathrm{O}, \delta^{2} \mathrm{H}$ 和 $d$ 明 显高于喜马拉雅山脉北面青藏高原南部地区．青藏 高原南部的聂拉木、定日和拉萨站夏季降水 $d$ 均值非 常接近, 而位于青藏高原中部纳木错降水 $d$ 均值 $11.1 \%$ o则比这 3 个站点的 $d$ 均值 $4.5 \%$ 高 $6.6 \%$, 该现 象很可能是由于纳木错湖水蒸发水汽与大气水汽混 合的结果. 同时, 纳木错流域夏季降水中 $d$ 值相对其 南部地区较高的特征, 在河水中 $d$ 值上也有很好的体 现. 其河水中 $d$ 均值为 $12.4 \%$ ，明显高于纳木错南部 上风向区域的河水中 $d$ 均值 $6.9 \%$. 此外, 初步估算 出近年夏季纳木错湖水蒸发水汽对当地大气水汽的 贡献率约为 $28.4 \%$ 31.1\%. 本文纳木错湖水蒸发水汽 对大气水汽贡献率的估算结果只是基于目前有限的 水体稳定同位素和气象资料的基础上做的一个初步 估算，其准确性和可靠性还有待将来更丰富的相关 数据(特别是实测的大气水汽数据)和进一步研究来 提高和证实.

\section{参考文献}

1 Fujinami H, Yasunari T. The seasonal and intraseasonal variability of diuranal cloud activity over the Tibetan Plateau. J Meteor Soc, 2001, 79: $1207-1227$

2 Kuwagata T, Numaguti A, Endo N. Diurnal variation of water vapor over the central Tibetan Plateau during summer. J Meteor Soc, 2001, 79: 401-418 
3 Xu J Q, Haginoya S. An estimation of heat and water balances in the Tibetan Plateau. J Meteor Soc, 2001, 79: 485-504

4 Li C, Yanai M. The onset and interannual variability of the Asian summer monsoon in relation to land-sea thermal contrast. J Clim, 1996, 9: 358-375

5 Luo H, Yanai M. The large-scale circulation and heat sources over the Tibetan Plateau and surrounding areas during the early summer of 1979. Part II: Heat and moisture budgets. Mon Weather Rev, 1984, 112: 966-989

6 Yanai M, Li C, Song Z. Seasonal heating of the Tibetan Plateau and its effects on the evolution of the Asian summer monsoon. J Meteor Soc, 1992, 70: 319-351

7 王跃男, 张博, 陈隆勋, 等. 夏季青藏高原大气热源与东亚大气热源及环流的关系. 科学通报, 2008, 53: 1842-1848

8 Chen L X, Reiter E R, Feng Z Q. The atmospheric heat source over the Tibetan Plateau from May to August, 1979. Mon Weather Rev, 1985, 113: $1771-1790$

9 Kuraosaki Y, Kimura F. Relationship between topography and daytime cloud activity around the Tibetan Plateau. J Meteor Soc, 2002, 80: 1339-1355

10 Fujinami H, Nomura S, Yasunari T. Characteristics of diurnal variations in convection and precipitation over the southern Tibetan Plateau during summer. SOLA, 2005, 1: 49-52

11 Xu J Q, Yu J, Liu S, et al. The implication of heat and water balance change in a lake basin on the Tibetan Plateau. Hydrol Res Lett, 2009, 3: $1-5$

12 杨伟愚, 叶笃正, 吴国雄. 夏季青藏高原热力场和环流场的诊断分析 I . 盛夏高原西部地区的水汽状况. 大气科学, 1992, 16: 41-51

13 姚檀栋，丁良福，蒲建辰，等. 青藏高原唐古拉山地区降雪中 $\delta^{18} \mathrm{O}$ 特征及其与水汽来源的关系. 科学通报, 1991, 36: 1570-1573

14 Kurita N, Yamada H. The role of local moisture recycling evaluated using stable isotope data from over the middle of the Tibetan Plateau during the monsoon season. J Hydrometeorol, 2008, 9: 760-775

15 Gat J R, Matsui E. Atmospheric water balance in the Amazon Basin: An isotopic evapotranspiration model. J Geophys Res-Atmos, 1991, 96: 13179-13188

16 Gat J R, Bowser C J, Kendall C. The contribution of evaporation from the Great Lakes to the continental atmosphere: Estimate based on stable isotope data. Geophys Res Lett, 1994, 21: 557-560

17 Worden J, Noone D, Bowman K. Imporatance of rain evaporation and continental convection in the tropical water cycle. Nature, 2007, 445: $528-532$

18 Yamanaka T, Shimizu R. Spatial distribution of deuterium in atmospheric water vapor: Diagnosing sources and the mixing of atmospheric moisture. Geochim Cosmochim Acta, 2007, 71: 3162-3169

19 Gat J R, Klein B, Kushnir Y, et al. Isotope composition of air moisture over the Mediterranean Sea: An index of the air-sea interaction pattern Tellus, 2003, 55: 953-965

20 Vallet-Coulomb C, Gasse F, Sonzogni C. Seasonal evolution of the isotopic composition of atmospheric water vapour above a tropical lake: Deuterium excess and implication for water recyling. Geochim Cosmochim Acta, 2008, 72: 4661-4674

21 Brock B E, Yi Y, Clogg-Wright K P, et al. Multi-year landscape assessment of lakewater balances in the Slave River Delta, NWT, using water isotope tracers. J Hydrol, 2009, 379: 81-91

22 Ingraham N L, Taylor B E. Light stable isotopes systematics of large scale hydrologic regimes in California and Nevada. Water Resour Res, 1991, 27: 77-90

23 陈锋, 康世昌, 张拥军, 等. 纳木错流域冰川和湖泊变化对气候变化的响应. 山地学报, 2009, 27: 641-647

24 吕雅琼，马耀明，李茂善. 西藏纳木错湖区大气边界层结构分析. 高原气象, 2008, 27: 733-740

25 Haginoya S, Fujii H, Kuwagata T, et al. Air-lake interaction features found in heat and water exchanges over Nam Co on the Tibetan Plateau. SOLA, 2009, 5: 172-175

26 Craig H, Gordon L I. Deuterium and oxygen 18 variations in the ocean and the marine atmosphere. In: Schink D R, Corless J T, eds. Symposium on Marine Geochemistry. Rhode Island: University of Rhode Island Press, 1965. 277-374

27 Merlivat L, Jouzel J. Global climatic interpretation of the deuterium-oxygen 18 relationship for precipitation. J Geophys Res, 1979, 84: 5029-5033

28 Dansgaard W. Stable isotopes in precipitation. Tellus, 1964, 16: 436-468

29 Craig H. Isotopic variations in meteoric waters. Science, 1961, 133: 1702-1703

30 Horita J, Wesolowski D. Liquid-vapour fraction of oxygen and hydrogen isotopes of water from the freezing to the critical temperature. Geochim Cosmochim Acta, 1994, 58: 3425-3437

31 Yi Y, Brock B E, Falcone M D, et al. A coupled isotope tracer method to characterize input water to lakes. J Hydrol, 2008, 350: 1-13

32 Horita J, Wesolowski D. Liquid-vapour fraction of oxygen and hydrogen isotopes of water from the freezing to the critical temperature. Geochim Cosmochim Acta, 1994, 58: 3425-3437

33 Gonfiantini R. Environmental isotopes in lake studies. In: Fritz P, Fontes J C, eds. Handbook of Environmental Isotope Geochemistry. Amsterdam: Elsevier Scientific Publishing Company, 1986. 113-168 
34 Jouzel J, Merlivat L. Deuterium and oxygen 18 in precipitation: Modeling of the isotopic effects during snow formation. J Geophys ResAtmos, 1984, 89: 11749-11758

35 Tian L D, Yao T D, MacClune K, et al. Stable isotopic variations in west China: A consideration of moisture sources. J Geophys Res-Atmos, 2007, 112, doi:10.1029/2006JD007718

36 Tian L D, Masson-Delmotte V, Stievenard M, et al. Tibetan Plateau summer monsoon northward extent revealed by measurements of water stable isotopes. J Geophys Res-Atmos, 2001, 106: 28081-28088

37 Tian L D, Yao T D, Schuster P F, et al. Oxygen-18 concentrations in recent precipitation and ice cores on the Tibetan Plateau. J Geophys Res-Atmos, 2003, 108, doi:10.1029/2002JD002173

38 徐彦伟. 青藏高原纳木错流域水体稳定同位素研究. 博士学位论文. 北京: 中国科学院研究生院, 2010. 59-66

39 Gupta S K, Deshpande R D, Bhattacharya S K, et al. Groundwater $\delta^{18} \mathrm{O}$ and $\delta \mathrm{D}$ from central Indian Peninsula: Influence of the Arabian Sea and the Bay of Bengal branches of the summer monsoon. J Hydrol, 2005, 303: 38-55

40 Kang S C, Kreutz K J, Mayewski P A, et al. Stable-isotopic composition of precipitation over the northern slope of the central Himalaya. J Glaciol, 2002, 48: 519-526

41 高坛光, 康世昌, 周石研, 等. 纳木错曲嘎切流域夏季冰川水文特征初步研究. 冰川冻土, 2009, 31: 725-731

42 Tian L D, Yao T D, Sun W Z, et al. Relationship between $\delta \mathrm{D}$ and $\delta^{18} \mathrm{O}$ in precipitation in north south of the Tibetan Plateau moisture recycling. Sci China Ser D-Earth Sci, 2001, 44: 789-796

43 Tian L D, Liu Z F, Gong T L, et al. Isotopic variation in the lake water balance at the Yamdruk-tso basin, southern Tibetan Plateau. Hydrol Process, 2008, 22: 3386-3392

44 Jacob H, Sonntag C. An 8-year record of the seasonal variation of ${ }^{2} \mathrm{H}$ and ${ }^{18} \mathrm{O}$ in atmospheric water vapour and precipitation at Heidelberg, Germany. Tellus Ser B-Chem \& Phys Meteor, 1991, 43: 291-300

45 Zuber A. On the environmental isotope method for determining the water balance components of some lakes. J Hydrol, 1983, 61: 409-427

46 Gibson J J, Birks S J, Edwards T W D. Global prediction of $\delta_{\mathrm{A}}$ and $\delta^{2} \mathrm{H}-\delta^{18} \mathrm{O}$ evaporation slopes for lakes and soil water accounting for seasonality. Glob Biogeochem Cycle, 2008, 22: GB2031 